\title{
Prognostic factors and long-term outcomes following a modified Thompson's quadricepsplasty for severely stiff knees
}

\author{
S. B. Hahn, \\ Y. R. Choi, \\ H. J. Kang, \\ S. H. Lee \\ From Yonsei \\ University College of \\ Medicine, Seoul, \\ Korea
}

\begin{abstract}
Between 1987 and 2006 we performed a modified Thompson's quadricepsplasty on 40 fracture-related stiff knees and followed the patients for a mean of 7.9 years (2 to 11.1). The factors affecting the final gain of movement were investigated. A total of 15 knees required lengthening of the rectus femoris. The mean flexion gain was $70.2^{\circ}\left(42.3^{\circ}\right.$ to $\left.112.5^{\circ}\right)$. According to Judet's criteria, the results were excellent in $\mathbf{3 0}$ knees, good in seven, and fair in three. The range of movement which was achieved intra-operatively was related to the gain of knee flexion on univariate analysis. Five patients had complications: deep infection in one, recurrent patellar dislocation in one, and rupture of the extensor mechanism in three. This modified technique gives satisfactory results. Achieving maximum knee flexion intraoperatively seems to be the most important factor in enhancing the outcome in patients with stiffness of the knee following fracture.
\end{abstract}

A stiff knee most commonly occurs after a traumatic injury, particularly a fracture in the supracondylar region of the femur. ${ }^{1-4}$ Quadricepsplasty is a surgical procedure designed to increase knee flexion in patients with a severe extension contracture of the knee joint. Various techniques, such as the Thompson ${ }^{4}$ and Judet procedures ${ }^{5}$ and their modifications, have been described to increase range of movement (ROM). However, most of these techniques raise concerns regarding clinical outcomes and complications. ${ }^{6-8}$ To the best of our knowledge, there have been no reports examining the factors that influence the intraoperative complications and final ROM. Analysis of the prognostic factors affecting the long-term outcome and complications could improve the results and prevent complications.

The original Thompson's quadricepsplasty involves stripping the rectus femoris from the other vastus muscles, and releasing the vastus lateralis and vastus medialis from either side of the patella using a longitudinal mid-line incision. ${ }^{3,4,9}$ There is a high rate of morbidity (as high as $67 \%),{ }^{10}$ including skin necrosis and extension lag associated with this procedure. In order to circumvent this, in 2000 we described a modified technique and reported good results without serious complications. ${ }^{11}$

The aim of this study was to see whether an extension lag is a permanent complication following lengthening of the rectus femoris and also to study the factors that might affect gain in ROM, especially in patients with stiff knees following a fracture.

\section{Patients and Methods}

We retrospectively reviewed the records of 42 patients with a stiff knee (43 knees) who underwent a modified Thompson's quadricepsplasty between March 1987 and August 2006. The operation was performed by a single surgeon (SBH). This included further follow-up of 19 patients ( 20 knees) from the earlier series. ${ }^{11}$ Stiffness was secondary to fracture in 40 patients, to femoral lengthening in one patient with achondroplasia (two knees) and following correction of femoral and tibial deformities in one patient with rickets. A total of 40 patients, 35 males and five females with a mean age of 35.4 years (17 to 66) with fracture-related stiffness of the knee were included in the study. The fractures included a comminuted femoral supracondylar fracture in 18 patients, a comminuted supracondylar femoral fracture combined with a patellar fracture in seven, a femoral shaft fracture in nine, a femoral shaft fracture combined with a patellar fracture in two, and a proximal tibial fracture in four. The mean interval between the injury or previous operation and modified quadricepsplasty was 40.3 months (12 to 240$)$. The mean follow-up was 7.9 years (2 to 11.1 ) (Table I).

The technique has been described in detail previously. ${ }^{11}$ Under general or spinal anaesthe- 
Table I. Clinical data of the patients with stiff knees

\begin{tabular}{ll}
\hline Ratio of patients (male:female) & $35: 5$ \\
Age (range) in years & 35.4 (17 to 66) \\
Cause of stiffness (number of patients) & 18 \\
$\quad$ Femoral supracondylar fracture alone & 7 \\
$\quad$ Femoral supracondylar fracture with patellar fracture & 9 \\
$\quad$ Femoral shaft fracture alone & 2 \\
$\quad$ Femoral shaft fracture with patellar fracture & 4 \\
$\quad$ Proximal tibial fracture & 37.9 (0 to 85) \\
Mean pre-operative movement (range) $\left(^{\circ}\right)$ & 40.3 (12 to 240) \\
Mean time from initial trauma to the index operation (range) & \\
(mths) & 7.9 (2 to 11.1) \\
Mean follow-up (range) (yrs)
\end{tabular}

sia, the patient is placed in the supine position. A tourniquet is applied to the proximal thigh and medial and lateral parapatellar incisions are made to release the medial and the lateral retinaculum and their adhesions to the femoral condyles, the suprapatellar pouch, and intra-articular adhesions (stage 1). The knee is then flexed, and if adequate flexion is not achieved an anterolateral or lateral incision is made in the distal two-thirds of the thigh to release adhesions around the quadriceps muscle. The tensor fascia lata is divided transversely in the distal thigh. The vastus lateralis is freed from the rectus femoris and from its insertion into the patella. The vastus medialis is also released from the rectus femoris and distal femur, but the insertion into the superomedial aspect of the patella is preserved to prevent lateral subluxation of the patella and weakness of the extensor mechanism. The rectus femoris is released from the vastus intermedius, the anterior surface of the femur and the upper pole of the patella (stage 2).

In 15 knees, Z-lengthening of the rectus femoris is performed to achieve $110^{\circ}$ or more flexion of the knee (stage 3 ). Following tenotomy, gentle manipulation of the knee in flexion is performed to achieve maximum flexion. The lengthened rectus femoris tendon is then sutured with the knee in maximum flexion. After releasing the tourniquet, meticulous haemostasis is obtained, and only the skin sutured over a suction drain. The knee is immobilised in flexion with a bandage in a figure-of-eight configuration allowing exposure of the wound so that the blood supply can be observed. The knee is usually immobilised in $10^{\circ}$ of flexion less than the maximum obtained to allow adequate circulation to the wound.

The knee is immobilised post-operatively periodically in flexion and full extension at three-hourly intervals during the day. At night, the knee is positioned in $45^{\circ}$ of flexion for six hours. The periodic passive ROM and quadriceps strengthening exercises are continued for four weeks on an in-patient basis. However, a continuous passive movement machine was used on five patients who could not tolerate the passive exercise regime. Active and passive ROM and quadriceps strengthening exercises are continued for six months.

The ROM of the knee in the supine position was recorded using a standard goniometer pre-operatively, at four weeks post-operatively, and at the last follow-up. The clinical results were estimated using Judet's criteria, ${ }^{5}$ with flexion $>100^{\circ}$ being an excellent result, $81^{\circ}$ to $100^{\circ}$ being good, $50^{\circ}$ to $80^{\circ}$ being fair, and $<50^{\circ}$ a poor result.

Statistical analysis. The paired-samples $t$-test was used for comparison between the pre-operative and the final ROM of the knee. Univariate regression analysis was performed to determine whether there was a significant association between each of the pre-operative and operation-related variables and the final gain in flexion. All analyses were performed with SPSS, version 12.0 (SPSS Inc., Chicago, Illinois) and a p-value $<0.05$ was considered significant.

\section{Results}

The mean pre-operative flexion contracture and further active flexion of the knee were $4.38^{\circ}\left(0^{\circ}\right.$ to $\left.30^{\circ}\right)$ and $42.3^{\circ}$ $\left(0^{\circ}\right.$ to $\left.85^{\circ}\right)$, respectively. Thus, the mean pre-operative ROM was $37.9^{\circ}\left(0^{\circ}\right.$ to $\left.85^{\circ}\right)$. The mean ROM achieved at operation was $115.9^{\circ}\left(75^{\circ}\right.$ to $\left.140^{\circ}\right)$. At the final follow-up, the mean flexion contracture and further active flexion of the knee were $2.1^{\circ}\left(0^{\circ}\right.$ to $\left.20^{\circ}\right)$ and $112.5^{\circ}\left(55^{\circ}\right.$ to $\left.150^{\circ}\right)$, respectively, and the mean $\mathrm{ROM}$ was $110.4^{\circ}\left(55^{\circ}\right.$ to $\left.150^{\circ}\right)$. Therefore the overall mean flexion gain at final follow-up was $70.2^{\circ}$. There were eight flexion contractures: three of $5^{\circ}$, three of $10^{\circ}$, and two of $20^{\circ}$. Two patients with a flexion contracture of $20^{\circ}$ were from the earlier series. ${ }^{11} \mathrm{~A}$ mean flexion gain was $70.3^{\circ}$ $\left(5^{\circ}\right.$ to $\left.110^{\circ}\right)$ at the final follow-up ( $\left.\mathrm{p}<0.001\right)$ (Table II). Lengthening of the rectus femoris was required in 15 knees, 12 of which had a mean extension lag of $11.0^{\circ}\left(10^{\circ}\right.$ to $\left.20^{\circ}\right)$ at the completion of the physiotherapy programme six months after operation. However, none of the patients with rectus femoris lengthening had an extension lag or extensor weakness at the final follow-up. ${ }^{5}$ The results were excellent for 30 knees, good for seven, and fair for three.

If the data from the 17 patients with fracture-related stiffness in the earlier series are excluded, the mean active flexion and the final gain in knee flexion were $113.6^{\circ}\left(55^{\circ}\right.$ to $\left.140^{\circ}\right)$ and $71.4^{\circ}\left(35^{\circ}\right.$ to $\left.110^{\circ}\right)$ in 11 patients of 23 without rectus femoris lengthening, but $109.9^{\circ}\left(85^{\circ}\right.$ to $\left.150^{\circ}\right)$ and $78.8^{\circ}\left(40^{\circ}\right.$ to $\left.105^{\circ}\right)$ in the remaining 12 patients with rectus femoris lengthening. These discrepancies seem to indicate the impact of rectus femoris lengthening, which is 
Table II. Clinical outcomes

\begin{tabular}{lcrr}
\hline & Pre-operative $\left(^{\circ}\right)$ & Intraoperative $\left(^{\circ}\right)$ & Last follow-up $\left(^{\circ}\right)$ \\
\hline $\mathrm{FC}^{*}$ (range) & $4.4(0$ to 30$)$ & $3.9(0$ to 20$)$ & $2.1(0$ to 20$)$ \\
$\mathrm{FF}^{\dagger}$ (range) & $42.3(0$ to 85$)$ & $119.8(75$ to 140$)$ & $112.5(55$ to 150$)$ \\
$\mathrm{ROM}^{\ddagger}$ (FF - FC) (range) & $37.9(0$ to 85$)$ & $115.9(75$ to 140$)$ & $110.4(55$ to 150$)$ \\
\hline${ }^{*} \mathrm{FC}$, flexion contracture & & & \\
$\dagger \mathrm{FF}$, further flexion & & & \\
‡ ROM, range of movement & & &
\end{tabular}

essential in patients with a severe extension contracture of the knee. The results of the earlier series, $113.5^{\circ}\left(75^{\circ}\right.$ to $\left.150^{\circ}\right)$ and $67.6^{\circ}\left(5^{\circ}\right.$ to $\left.105^{\circ}\right)$ in the same order were similar to the results of the patients without rectus femoris lengthening because there were only four of 20 who had rectus femoris lengthening.

Univariate analysis was carried out to investigate the relationship between pre-operative or operation-related variables (e.g. age, gender, the interval between the injury or initial surgery and the index procedure, pre-operative values determining ROM, lengthening of the rectus femoris, and complications) and the final gain of flexion (Table III). The gain in flexion at the final follow-up was significantly affected by the pre-operative ROM and the intra-operative ROM achieved $(\mathrm{p}<0.05)$.

There were five complications. One patient had a deep infection, which resolved three weeks later after incision and drainage and the administration of intravenous antibiotics. However, this patient finally had only $10^{\circ}$ of improvement. The extensor mechanism ruptured in three patients per-operatively during manipulation of the knee prior to lengthening of the rectus femoris; with an avulsion fracture of the tibial tuberosity in one patient, rupture of the patellar tendon in one, and a patellar fracture in one. The avulsion fracture and the rupture were repaired using suture anchors and tension band wiring; the knee was immobilised in extension for six weeks and ROM exercises were commenced gradually. The final active knee flexion was $115^{\circ}$ and $55^{\circ}$ respectively, with no extension lag. The patellar fracture was managed conservatively, and a continuous passive motion machine was used for passive movement exercises. The fracture healed satisfactorily and the final active flexion was $90^{\circ}$. The final complication was a recurrent lateral dislocation of the patella following separation of the patella from the femoral trochlea in a patient with pre-operative traumatic synostosis of the patellofemoral joint (Fig. 1). In this patient, the loss of bony congruency between the patella and femoral condyles induced a dislocation. After proximal and distal extensor realignment procedures, the patella was reduced and the final active flexion was $105^{\circ}$ (Fig. 1).

\section{Discussion}

Scarring of the extensor mechanism can lead to a severe extension contracture of the knee. The factors that limit flexion of the knee include adhesions at the patellofemoral
Table III. Results of univariate analysis for predictors of final gain of knee flexion

\begin{tabular}{lcr}
\hline Variables & Regression coefficient & p-value \\
\hline Gender & -2.571 & 0.833 \\
Age & 0.165 & 0.587 \\
Duration of stiffness & 0.007 & 0.936 \\
& & \\
ROM & & \\
$\quad$ Pre-operative & -0.764 & 0.001 \\
$\quad$ Intra-operative & 0.483 & 0.043 \\
& & \\
Lengthening of the RF & 15.067 & 0.064 \\
Complication & -14.000 & 0.246 \\
\hline * ROM, range of movement; RF, rectus femoris
\end{tabular}

joint; fibrosis and shortening of the vastus medialis and the vastus lateralis and adhesion to the femoral condyles; scarring and fibrosis of the vastus intermedius; and shortening of the rectus femoris. ${ }^{3,5}$ Of the various techniques for quadricepsplasty, Thompson's and Judet's have been the most popular. The most distinct difference between the two techniques is the site of release of the quadriceps mechanism: release at the site of insertion in Thompson's technique uses an anterior midline incision and release at the site of origin in Judet's technique uses a long lateral incision. ${ }^{12}$ As a result, Judet's quadricepsplasty requires a much more extensive dissection and precludes the use of a tourniquet. Thompson's technique, on the other hand, has inherent weaknesses, such as delayed wound healing, infection, and an extension lag as the rectus femoris is isolated from the rest of the quadriceps through an anterior midline incision, ${ }^{5,8,13}$ which was the main reason for seeking a modification of the technique. Ischaemia of the skin over the patella can be induced by flexing the knee, especially in patients with a long-standing extension contracture. ${ }^{13}$ If a long midline incision is used in knees with a contracture and poor soft tissues, vigorous exercise should be postponed until wound healing has occurred. In the modified technique, two small parapatellar incisions and a lateral or anterolateral incision on the distal thigh are made to reduce possible problems with wound healing while preserving the insertion of the vastus medialis at the superomedial corner of the patella when rectus femoris lengthening is required. 


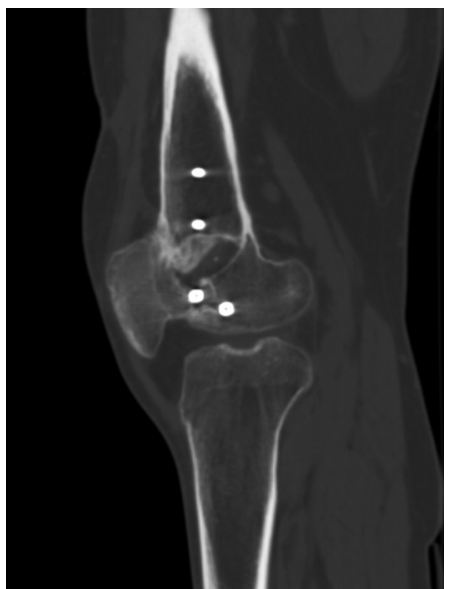

Fig. 1a

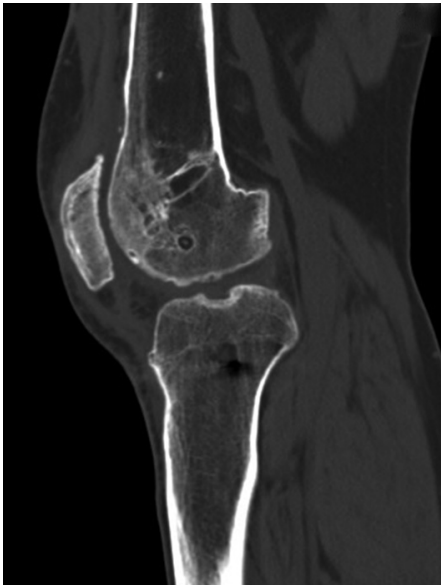

Fig. 1b

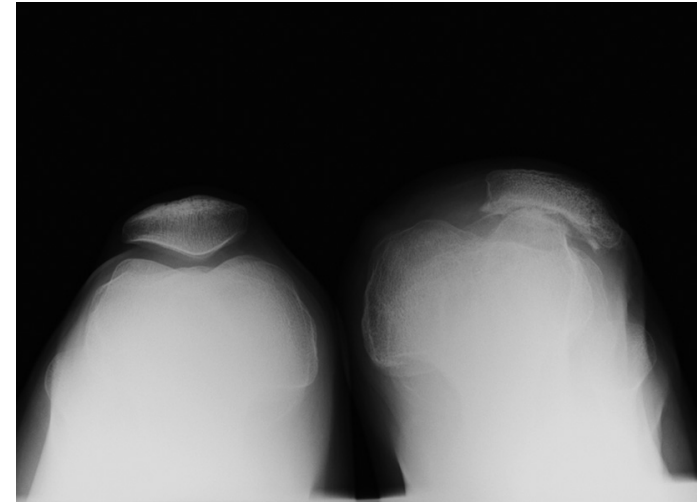

Fig. 1c

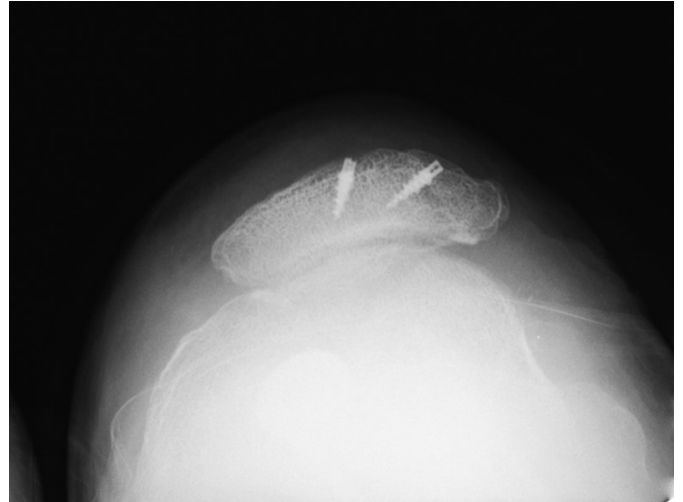

Fig. 1d

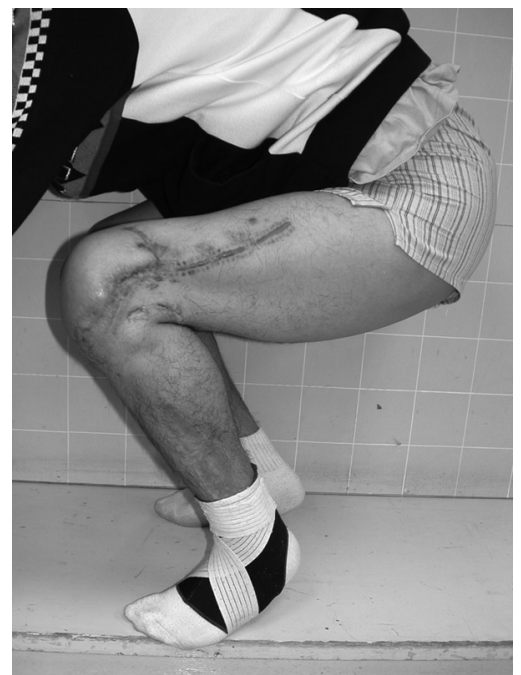

Fig. 1e

An 18-year-old man had nonunion of a distal femoral fracture and traumatic synostasis of the patellofemoral joint after a grade IIIA open AO/ASIF C2 supracondylar fracture CT scan showing (a) Autograft from the iliac crest at the nonunion site and (b) division of the patella from the patellar groove of the distal femur were performed. After achieving bony union at the site of nonunion, a modified Thompson's quadricepsplasty was performed, including lengthening of the rectus femoris. However, recurrent dislocation of the patella occurred (c). (d) The patella was reduced with proximal and distal extensor realignment procedures. Photograph 26 months after operation showing that (e) $110^{\circ}$ of flexion was achieved. There was full extension and the final result was excellent.

In our series, the mean maximum flexion was $112.5^{\circ}$ $\left(55^{\circ}\right.$ to $\left.150^{\circ}\right)$ and the mean $\mathrm{ROM}$ was $110.4^{\circ}\left(55^{\circ}\right.$ to $\left.150^{\circ}\right)$, with $70.3^{\circ}\left(5^{\circ}\right.$ to $\left.110^{\circ}\right)$ of mean flexion gain at a mean follow-up of 7.9 years. Of the 40 patients, $37(92.5 \%)$ showed good or excellent results. Our findings are comparable to those that have already been published. ${ }^{5,14-16}$ However, high rates of extension lag after quadricepsplasty from $8^{\circ}$ to $52^{\circ}$ have also been reported..$^{2,3,9,17,18}$ Lengthening of the rectus femoris has been considered to be the causative factor. ${ }^{3}$ In our series, lengthening of the rectus femoris was required in 15 knees, 12 of which had a mean extension lag of $11.0^{\circ}$ on completion of the post-operative rehabilitation programme. All patients with an extension lag had gradual improvement of extension power and reduction in the lag with quadriceps stretching and strengthening exercises. Our promising results were probably due to the modification of Thompson's technique and the intensive postoperative rehabilitation programme, periodic passive movement and quadriceps strengthening exercises. The core of our modified technique is preservation of the connection to the superomedial corner of the patella of the vastus medialis and the use of anterolateral or lateral incisions to avoid anterior incisions. These modifications also allowed early and intensive post-operative rehabilitation.

Univariate analysis identified two factors affecting the final gain of flexion. Pre-operative ROM of the knee had a 
negative regression coefficient and the ROM which was achieved intra-operatively had a positive regression coefficient (Table II). These results were similar to those of Masse et al, ${ }^{15}$ whose analysis of the long-term results of Judet's quadricepsplasty also showed a reverse correlation between the final flexion gain and the pre-operative flexion. Moreover, our results also showed that the ROM which is achieved intra-operatively might be the most important determining factor for final gain of flexion.

We had five complications in our series. Rupture of the extensor mechanism occurred on three occasions during forceful manipulation in an attempt to avoid lengthening of the rectus femoris. These complications could have been avoided if lengthening had been performed when satisfactory gain of knee flexion could not be achieved. These patients had $55^{\circ}, 90^{\circ}$ and $115^{\circ}$ of flexion, respectively at the final follow-up.

Despite several complications, most of our patients achieved a meaningful improvement of knee flexion following modified Thompson's quadricepsplasty after two or more years of follow-up. We recommend that surgeons should consider rectus femoris lengthening if satisfactory knee flexion cannot be obtained with gentle passive manipulation after adhesiolysis around the knee joint in order to avoid rupture of the extensor mechanism.

There are several limitations to this study. First, it was retrospective, and included patients with different fractures. Because of this, only pre-operative factors were analysed to assess those factors which might affect the final functional outcome. Another limitation is that there are no comparative data available in terms of other types of quadricepsplasty. Finally, we only used active ROM to estimate the final functional outcome. However, the objective of a quadricepsplasty is primarily to restore flexion of the knee, and Judet's criteria, which reflect the maximum flexion obtained, have been the most widely used method to determine the outcome of patients with a stiff knee.

The authors wish to thank H.-Y. Jung for his efforts in the preparation of the manuscript.

No benefits in any form have been received or will be received from a commercial party related directly or indirectly to the subject of this article.

\section{References}

1. Bellemans J, Steenwerckx A, Brabants K, et al. The Judet quadricepsplasty: a retrospective analysis of 16 cases. Acta Orthop Belg 1996;62:79-82.

2. Ikpeme Jo. Quadricepsplasty following femoral shaft fractures. Injury 1993;24:104-8.

3. Nicoll EA. Quadricepsplasty. J Bone Joint Surg [Br] 1963;45-B:483-90.

4. Thompson TC. Quadricepsplasty. Ann Surg 1945;121:751-4.

5. Judet R. Mobilization of the stiff knee. J Bone Joint Surg [Br] 1959;41-B:856-7.

6. Hosalker HS, Jones S, Chowdury M, Hartley J, Hill RA. Quadricepsplasty for knee stiffness after femoral lengthening in congenital short femur. J Bone Joint Surg [Br] 2003;85-B:261-4

7. Wang JH, Zhao JZ, He YH. A new treatment strategy for severe arthrofibrosis of the knee: a review of twenty-two cases. J Bone Joint Surg [Am]2006;88-A:1245-50.

8. Warner JJ. The Judet quadricepsplasty for management of severe posttraumatic extension contracture of the knee: a report of a bilateral case and review of the literature. Clin Orthop 1990;256:169-73.

9. Hesketh KT. Experiences with the Thompson quadricepsplasty. J Bone Joint Surg [Br] 1963;45-B:491-5.

10. Moore TJ, Harwin C, Green SA, Garland DE, Chandler RW. The results of quadricepsplasty on knee motion following femoral fractures. J Trauma 1987;27:49-51.

11. Hahn SB, Lee WS, Han DY. A modified Thompson quadricepsplasty for the stiff knee. J Bone Joint Surg [Br] 2000;82-B:992-5.

12. Alici T, Buluc L, Tosun B, Sarlak AY. Modified Judet's quadricepsplasty for loss of knee flexion. Knee 2006;13:280-3.

13. Ebraheim NA, DeTroye RJ, Saddemi SR. Results of Judet quadricepsplasty. J Orthop Trauma 1993;7:327-30.

14. Ali AM, Villafuerte J, Hashmi M, Saleh M. Judet's quadricepsplasty, surgical technique, and results in limb reconstruction. Clin Orthop 2003:415:214-20.

15. Masse A, Biasibetti A, Demangos J, et al. The judet quadricepsplasty: long-term outcome of 21 cases. J Trauma 2006;61:358-62.

16. Merchan EC, Myong C. Quadricepsplasty: the Judet technique and results of 21 posttraumatic cases. Orthopedics 1992;15:1081-5.

17. Ratliff AH. Quadricepsplasty. Injury 1972;4:126-30.

18. Pick RY. Quadricepsplasty: a review, case presentations, and discussion. Clin Orthop 1976:120:138-42. 